\title{
Nutritional Status of Children and their Mothers, and its Determinants in Urban Capital and Rural Highland in Papua New Guinea
}

Miyoshi $\mathrm{M}^{\star 1,3}$, Hawap J ${ }^{2}$, Nishi $\mathrm{N}^{1}$ and Yoshiike $\mathrm{N}^{3}$

${ }^{1}$ Center for International Collaboration and Partnership, National institute of Health and Nutrition, Tokyo, Japan

${ }^{2}$ Department of Health, Port Moresby, Papua New Guinea

${ }^{3}$ Aomori University of Health and Welfare, Tokyo, Japan

${ }^{*}$ Corresponding author: Miyoshi M, Center for International Collaboration and Partnership, National institute of Health and Nutrition, Fax: +81-3-5287-3404, Tel: +81-3-3203-5721, E-mail: mikimiy@nih.go.jp Citation: Miyoshi M, Hawap J, Nishi N, Yoshiike N (2015) Nutritional Status of Children and their Mothers, and its Determinants in Urban Capital and Rural Highland in Papua New Guinea. J Nutr Health Sci 2(1): 102. doi: 10.15744/2393-9060.1.402

Received Date: November 27, 2014 Accepted Date: February 03, 2015 Published Date: February 09, 2015

\begin{abstract}
In Papua New Guinea (PNG), under-five mortality rate still remains high (69 per 1,000 live birth), and infectious diseases contribute to $38 \%$ of deaths among under-five children, possibly due to not only low immunization coverage but also undernutrition. The situation is especially serious in rural highland, where accessibility to foods available outside village is very limited due to poor infrastructure for transportation, leading to persistent food insecurity. Under this circumstance, this study was undertaken with the aim to assess nutritional status of children and their mothers in the urban capital (Port Moresby (POM)) and rural highland (Nuku district, Sandaun Province (NUKU)). Fieldwork was carried out in October 2010 in urban POM and in September 2011 in rural NUKU. In total 211 pairs of children aged 6-59 months and their mothers were measured for anthropometry following the standard method. Data on household characteristic, dietary intake, infant feeding practice, child's disease history and mother's lifestyle habit were obtained by interviews with mothers.

Prevalence of stunting and underweight was higher in rural NUKU than urban POM $(p<0.05)$. Whilst food insecurity was more serious in rural NUKU, morbidity of children was higher in urban POM. Distribution of mothers' BMI was quite different between two sites, with higher proportion of overweight/obesity in urban POM (47.6\%) and underweight in rural NUKU (10.8\%). People in POM appeared better-off, though it was recognized poor households were disadvantaged. Characteristics of infant feeding practice were also different between two sites. Early introduction of the first liquid/food other than breastmilk was associated with undernutrition among children. The findings of this study would suggest that area-specific approach for "double burden of malnutrition" should be enhanced, considering differential regional characteristics affecting the nutritional status of children and mothers in PNG.
\end{abstract}

Keywords: PNG; Food security; Maternal and child nutrition; Double burden of malnutrition

\section{Introduction}

In Papua New Guinea (PNG), despite a very slow decline of mortality for children under the age of five during the last two decades, mortality in this age group still remains high (69 per 1,000 live birth) [1]. Infectious diseases (e.g. malaria, ARI, diarrhea) contribute to $38 \%$ of deaths among under-five children, possibly due to not only low immunization coverage but also undernutrition [2]. The national average of stunting, underweight and wasting among under-five children is $43 \%, 18 \%$ and $5 \%$, respectively [1].

PNG is one of 77 countries classified as a "Low-Income and Food Deficit Country" by the Food and Agriculture Organization of the United Nations (FAO). This is based on the increasing food imports as well as per capita dietary energy supply [3]. Food insecurity in PNG is due to a variety of factors such as seasonal food shortage, the imbalance between local production and population growth, a wide income disparity, an increased dependency on cash income to purchase food items and the declining trade balance [4]. The situation is especially serious in rural highland, where accessibility to foods available outside village is very limited due to poor infrastructure for transportation, leading to persistent food insecurity $[3,5]$.

So far, the available data on the nationwide nutritional surveys were limited to the children under the age of five [6], or children aged 6-59 months and non-pregnant women of child bearing age 15-49 years [7]. However, none of these studies included dietary intake data, which is vital for nutritional assessment (e.g. to identify nutritional deficiency). While previous studies in 1980s and 1990s focused on nutritional adaptation to low protein PNG diets [8,9], it was also noted that slow growth was associated with slower development, reduced functional capacity and increased risk of serious illness and death [10]. Furthermore, there are no current studies on the situation analyses of the regional public health issues or the double burden of malnutrition in which undernutrition and overnutrition co-exist in a country. Under this circumstance, this study was undertaken with the aim to assess nutritional status of children and their mothers in the urban capital and rural highland, as well as to investigate the association with the possible determinants (e.g. socio-demographic or lifestyle factors). 


\section{Subjects and methods}

Study area

Fieldwork was carried out in October 2010 in Port Moresby (POM) for urban capital, and in September 2011 in Nuku district, Sandaun Province (NUKU) for rural highland. Total population of each study site is 254,158 and 46,021, respectively [11].

In PNG, routine immunizations are provided by the government and carried out by health clinic and center. In POM, "Well baby Clinic, Port Moresby General Hospital" was selected as a study site for data collection, as the largest health clinic belonging to a national hospital.

PNG is one of the most culturally diverse countries with 850 native languages. Study site of rural highland (NUKU) was identified based on the feasibility study conducted in July 2010. NUKU is located in the northwestern part of the mainland and had the highest annual average number of malnourished children in Sandaun Province (1991-1997) [12]. From POM, NUKU can be reached by domestic flight to Wewak ( 2 hours) first, followed by 8-10 hours' drive depending on the road condition. In NUKU, the data collection was carried out at the Nuku district Health Center.

\section{Selection of the study subjects}

All the mothers who visited the study clinic or health center for routine immunization of children aged 6-59 months, during our visit were explained about this study. Pregnant mothers were excluded. In total, 201 pairs (89 in POM and 112 in NUKU) of children aged 6-59 month and their mothers who agreed to participate joined in this study.

\section{Data collection}

Anthropometric measurements: Height/length, weight and Mid Upper Arm Circumference (MUAC) were measured for children and height, weight and abdominal circumference were measured for mothers. Height was measured using a "Seca Leicester Portable Height Measure (Seca, UK)" to the nearest $0.1 \mathrm{~cm}$, and recumbent length (for children $<2$ years) was measured using a "Rollameter 100 (Child Growth Foundation, UK)". Weight was measured using a digital scale "SECA877" with capacity of $200 \mathrm{~kg} \times 100 \mathrm{~g}$ (SECA, Japan). Children and mothers were weighed bare-foot, wearing minimal clothes, and their weight was recorded to the nearest $0.1 \mathrm{~kg}$. MUAC was also measured to assess their thinness, using an insertion tape with three coloured zones. A cut-off of $13.5 \mathrm{~cm}$ was used to classify the undernourished children $[13,14]$. A plastic tape measure was used to measure mothers' abdominal circumference. All the measurements were performed by a single person (Miyoshi) throughout the survey.

Questionnaire interview: Mothers were interviewed by the local village health workers who were recruited and trained for this study, using the structured questionnaires. Questions include the socio-demographic characteristics of the households (number of household member, birth order of study child, number of siblings, occupation as main income source, source of drinking water, type of toilet), child health (birth weight, disease history (fever, diarrhoea and cough in the past two weeks; malaria, measles and Acute Respiratory Infections (ARIs) in the past), mother's lifestyle habits and reproductive history (alcohol drinking, chewing betel nuts, smoking, number of pregnancy and delivery), and infant feeding practices (colostrum, duration of exclusive breastfeeding, first liquid other than breast milk and foods given to the child, timing to stop breastfeeding). Besides, dietary intake data of mothers and their children were obtained by 24-hour recall methods and Food Frequency Questionnaire (FFQ). Food list for FFQ was developed based on observation at the feasibility study in July 2010.

Data entry and analysis: Anthropometric data of children were entered into WHO Anthro [15], to calculate anthropometric indices, height-for-age Z-score (HAZ), weight-for-age Z-score (WAZ) and weight-for-height Z-score (WHZ). These calculated data were later transferred into IBM SPSS Statistics for further analyses with other variables. The chi-square $\left(\chi^{2}\right)$ test was performed to assess the association between categorical variables. The t-test was applied to compare the means of two groups. ANOVA was used to compare the means of several groups and the F-test was applied for the significance test. For $\chi^{2}$ test, $t$-test and F-test, 0.05 was taken as the level of statistical significance.

Ethics: Ethical approval was obtained from the Medical Research Advisory Committee, Department of Health, PNG on June 28, 2010 (Ref. MRAC No. 10.33), the ethical committee of the National Institute of Health and Nutrition on August 24,2010 (Ref. 20100824-01) and that of the Aomori University of Health and Welfare on June 29, 2011 (Ref. 11013).

\section{Results}

\section{Demographic characteristics of children and mothers}

Demographic characteristics of children and mothers, together with household characteristics are shown in Table 1. Mean ages of the child and mother were 11.1 months (SD: 5.9) and 28.2 years old (SD: 6.0) in urban POM and 32.5 months (SD: 17.2) and 30.1 years old (SD: 7.3) in rural POM.

The most common water and sanitation facilities for urban POM were tap water at home (94.3\%) and flushed toilet (84.1\%), whereas those for rural NUKU were deep well (73.0\%) and pit latrine (98.2\%). While a majority of the households in urban POM gain their income from employed jobs (except for two unemployed and one with support from church), more than half the households (71.4\%) in rural NUKU were subsistence farmers with sifting cultivation, livestock and foraging as their main source of livelihood. 


\begin{tabular}{|c|c|c|c|c|c|c|}
\hline & \multirow{2}{*}{ Variables } & \multirow{2}{*}{ Category } & \multicolumn{2}{|c|}{ Port Moresby $(n=89)$} & \multicolumn{2}{|c|}{ Nuku(n=112) } \\
\hline & & & $\mathbf{n}$ & $(\%)$ & $\mathbf{n}$ & $(\%)$ \\
\hline \multicolumn{7}{|l|}{ Children } \\
\hline & \multirow[t]{2}{*}{ Sex } & Boy & 39 & $(43.8)$ & 62 & (55.4) \\
\hline & & Girl & 50 & $(56.2)$ & 50 & $(44.6)$ \\
\hline & \multirow[t]{5}{*}{ Age } & 6- 12 months & 60 & $(67.4)$ & 19 & $((17.0)$ \\
\hline & & $12-23$ months & 26 & $(29.2)$ & 21 & $(18.8)$ \\
\hline & & 24-35 months & 1 & $(1.1)$ & 24 & $(21.4)$ \\
\hline & & $36-47$ months & 2 & (2.0) & 16 & $(14.3)$ \\
\hline & & 48-59 months & - & $(-)$ & 32 & (28.6) \\
\hline & \multirow[t]{5}{*}{ Birth order } & 1 & 36 & $(41.4)$ & 27 & $(24.1)$ \\
\hline & & 2 & 27 & $(31.0)$ & 21 & (18.8) \\
\hline & & 3 & 12 & $(13.8)$ & 19 & $(17.0)$ \\
\hline & & 4 & 7 & $(8.0)$ & 18 & $(16.1)$ \\
\hline & & $5 \leq$ & 5 & ( 5.6$)$ & 27 & $(24.1)$ \\
\hline \multicolumn{7}{|l|}{ Mothers } \\
\hline & \multirow[t]{4}{*}{ Age group } & $<20 \mathrm{yrs}$ & 4 & $(4.7)$ & 2 & $(2.0)$ \\
\hline & & $20-29$ yrs & 45 & $(52.3)$ & 48 & $(49.0)$ \\
\hline & & $30-39$ yrs & 33 & $(38.4)$ & 36 & $(36.7)$ \\
\hline & & $40 \mathrm{yrs} \leq$ & 4 & ( 4.7$)$ & 12 & $(12.2)$ \\
\hline & \multirow[t]{5}{*}{ No of delivery } & 1 & 34 & $(39.5)$ & 25 & (22.3) \\
\hline & & 2 & 28 & $(32.6)$ & 18 & (16.1) \\
\hline & & 3 & 11 & $(12.8)$ & 23 & (20.5) \\
\hline & & 4 & 7 & $(8.1)$ & 13 & (11.6) \\
\hline & & $5 \leq$ & 6 & $(7.0)$ & 33 & $(29.5)$ \\
\hline \multicolumn{7}{|c|}{ Households } \\
\hline & \multirow{5}{*}{$\begin{array}{l}\text { Source of } \\
\text { drinking water }\end{array}$} & Tap at home & 83 & $(94.3)$ & 17 & (15.3) \\
\hline & & Public tap & 1 & $(1.1)$ & 12 & $(10.8)$ \\
\hline & & Tank water & 2 & $(2.3)$ & 0 & $(0)$ \\
\hline & & Deep well & 1 & ( 1.1$)$ & 81 & $(73.0)$ \\
\hline & & River/spring & 1 & $(1.1)$ & 1 & $(0.9)$ \\
\hline & \multirow[t]{3}{*}{ Type of toilet } & Flush & 74 & $(84.1)$ & 0 & $(0)$ \\
\hline & & Pit latrine & 13 & $(14.8)$ & 109 & $(98.2)$ \\
\hline & & No toilet & 1 & ( 1.1$)$ & 2 & ( 1.8$)$ \\
\hline
\end{tabular}

Table 1: Characteristics of study children, mothers and households by study site

\section{Nutritional status and morbidity of children}

Prevalence of stunting (HAZ <-2) and underweight (WAZ < -2) was significantly higher in rural NUKU (Stunting 26.8\%, Underweight 8.9\%) than urban POM (Stunting 4.5\%, Underweight 2.2\%) (Table 2). In both sites, prevalence of stunting was significantly higher in boys than girls (POM $10.3 \%$ vs. $0.0 \%$, NUKU $30.6 \%$ vs. $22.0 \% ; p<0.05$ ). Within rural NUKU, children from a remote village (Namblo) were more likely to be undernourished compared to those living around the Nuku district health center, in terms of stunting, underweight and low MUAC $(<13.5 \mathrm{~cm})$. The number of children with low birth weight $(<2,500 \mathrm{~g})$ was seven for both sites. Out of seven reported in rural NUKU, six were reported in Namblo.

On the other hand, morbidity of children in the past 2 weeks were significantly higher in urban POM than rural NUKU; Diearrhoea ( $23.9 \%$ vs. $8.3 \%)$, Fever ( $45.4 \%$ vs. $17.3 \%$ ) and Cough (62.5\% vs. $30.0 \%$ ). Likewise, more children in urban POM, than in rural NUKU, have ever suffered from Malaria in the past $(5.7 \%$ vs. $0 \%)$. 


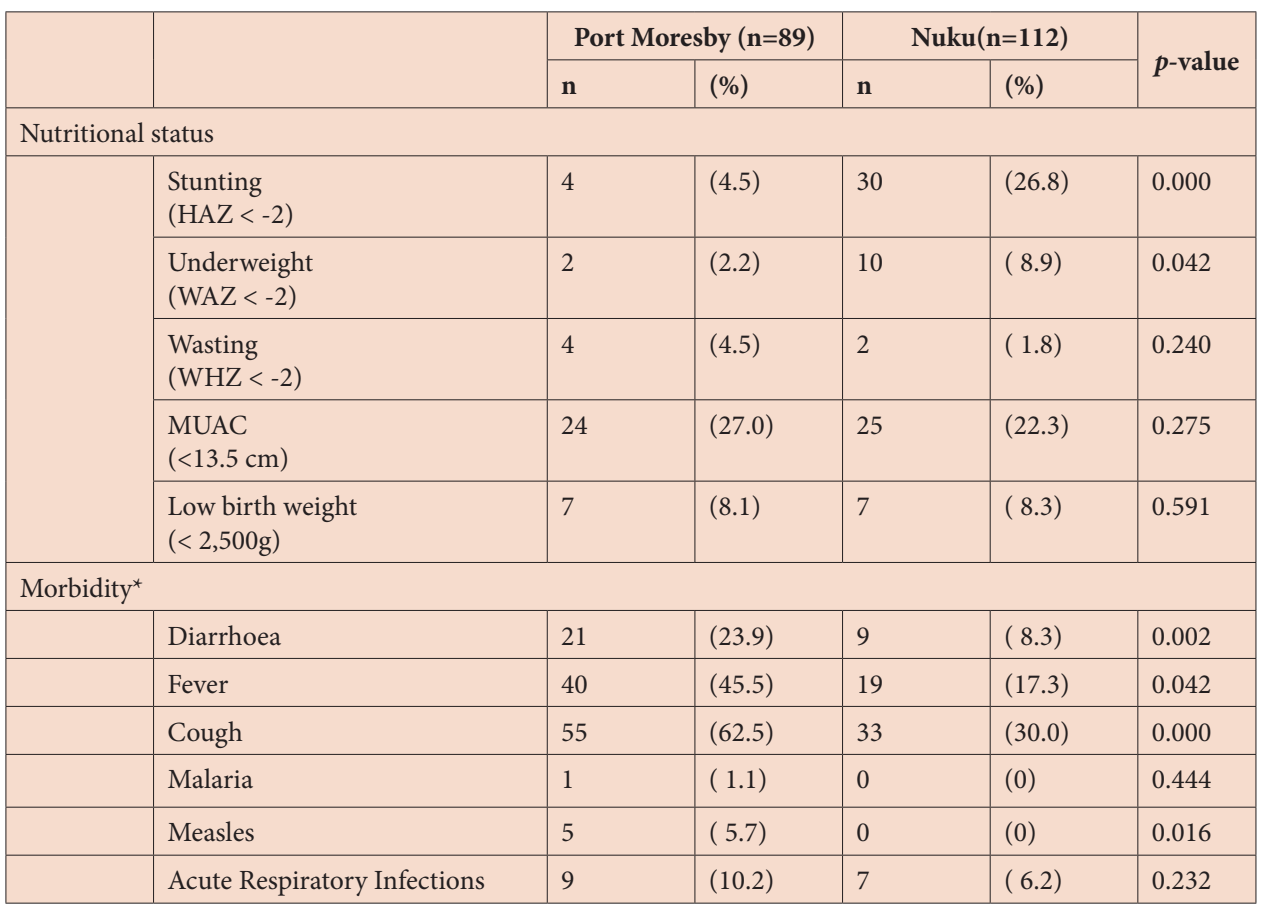

${ }^{*}$ Disease history in the past 2 weeks for diarrhoea, fever and cough, and in the past for malaria, measles and Acute Respiratory Infections.

Table 2: Prevalence of undernutrition and morbidity among children in study site

\section{Anthropometric status of mothers and lifestyle habits}

Prevalence of underweight (BMI < 18.5) was higher in rural NUKU $(10.8 \%)$ than in urban POM (5.8\%). Out of 12 underweight mothers in rural NUKU, seven were the mothers from Namblo. On the other hand, the prevalence of overweight $(25.0 \leq \mathrm{BMI}$ $<30.0$ ) and obesity $(\mathrm{BMI} \geq 30.0)$ among mothers was $26.7 \%$ and $20.9 \%$ in urban POM and $10.8 \%$ and $1.8 \%$ in rural NUKU, respectively In both sites, mothers' mean BMI increased with age groups (under 20 years, $20-29$ years, 30-39 years, over 40 years). The increase was statistically significant in urban POM (F-test: 6.28, $\mathrm{p}=0.001$ ), though significance was not detected in rural NUKU (F-test: 1.86, $\mathrm{p}=0.141$ ).

Table 3 shows the characteristics of mothers' lifestyle habits; alcohol intake, chewing betel nuts and smoking. Drinking is more common among mothers in urban POM (1-2 days/month (12.3\%), 1-2 days/week (3.3\%)). On the other hand, more frequent chewing betel nuts and smoking were reported in rural NUKU, compared to urban POM.

\begin{tabular}{|l|l|l|l|l|l|}
\hline \multirow{4}{*}{ variables } & Category & \multicolumn{2}{|c|}{ Port Moresby } & \multicolumn{2}{c|}{ Nuku } \\
\cline { 3 - 6 } & & $\mathbf{n}$ & $(\%)$ & $\mathbf{n}$ & $(\%)$ \\
\hline \multirow{4}{*}{$\begin{array}{l}\text { Alcohol } \\
\text { drinking }\end{array}$} & Every day & 0 & $(0)$ & 0 & $(0)$ \\
\cline { 2 - 6 } & $1-2$ days/week & 3 & $(3.3)$ & 0 & $(0)$ \\
\cline { 2 - 6 } & $1-2$ days/month & 11 & $(12.3)$ & 1 & $(0.9)$ \\
\cline { 2 - 6 } & Quit drinking & 6 & $(6.7)$ & 0 & $(0)$ \\
\cline { 2 - 6 } & Never/Hardly & 68 & $(76.4)$ & 109 & $(97.3)$ \\
\cline { 2 - 6 } & No answer & 1 & $(1.1)$ & 2 & $(1.8)$ \\
\hline \multirow{5}{*}{ betel nuts } & $\geq 6 /$ day & 21 & $(23.6)$ & 45 & $(40.2)$ \\
\cline { 2 - 6 } & $1-5 /$ day & 19 & $(21.3)$ & 14 & $(12.5)$ \\
\cline { 2 - 6 } & Once/day & 5 & $(5.6)$ & 5 & $(4.5)$ \\
\cline { 2 - 6 } & Not every day & 20 & $(22.5)$ & 19 & $(17.0)$ \\
\cline { 2 - 6 } & Never & 23 & $(25.8)$ & 27 & $(24.1)$ \\
\cline { 2 - 6 } & No answer & 1 & $(1.1)$ & 2 & $(1.8)$ \\
\hline Smoking & Everyday & 7 & $(7.9)$ & 23 & $(20.5)$ \\
\cline { 2 - 6 } & Sometimes & 7 & $(7.9)$ & 9 & $(8.0)$ \\
\cline { 2 - 6 } & No smoking & 73 & $(82.0)$ & 78 & $(69.6)$ \\
\cline { 2 - 6 } & No Answer & 2 & $(2.2)$ & 2 & $(1.8)$ \\
\hline
\end{tabular}

Table 3: Characteristics of lifestyle habit among mothers by study site 


\section{Association between mothers' BMI and anthropometric status of children}

Table 4 shows mean HAZ, WAZ and WHZ of children according to mothers' BMI. Children of underweight mothers had the lowest mean values of HAZ, WAZ and WHZ ( $\mathrm{p}<0.05$ for each in POM), though the association was not statistically significant in NUKU.

\begin{tabular}{|c|c|c|c|c|c|c|c|c|}
\hline & Mothers' BMI & & \multicolumn{2}{|c|}{ HAZ } & \multicolumn{2}{|c|}{ WAZ } & \multicolumn{2}{|c|}{ WHZ } \\
\hline \multirow[t]{6}{*}{ POM } & & $\mathbf{n}$ & Mean & (SD) & Mean & (SD) & Mean & (SD) \\
\hline & $<18.5$ & 5 & -1.80 & (1.52) & -1.65 & $(1.22)$ & -0.84 & (1.68) \\
\hline & $18.5-24.9$ & 40 & 0.67 & (1.16) & -0.06 & $(0.98)$ & -0.49 & (1.00) \\
\hline & $25.0-29.9$ & 23 & 0.06 & $(1.26)$ & 0.20 & $(0.84)$ & 0.32 & (1.09) \\
\hline & $30.0 \leq$ & 18 & 0.61 & (1.18) & 0.45 & $(0.93)$ & 0.26 & $(0.80)$ \\
\hline & F-test & \multicolumn{3}{|c|}{$6.91, \mathrm{p}=0.000$} & \multicolumn{2}{|c|}{$6.79, p=0.000$} & \multicolumn{2}{|c|}{$4.78, p=0.004$} \\
\hline \multirow[t]{6}{*}{ NUKU } & & $\mathbf{n}$ & Mean & (SD) & Mean & (SD) & Mean & (SD) \\
\hline & $<18.5$ & 12 & -1.79 & $(0.62)$ & -1.43 & $(0.62)$ & -0.55 & $(0.63)$ \\
\hline & $18.5-24.9$ & 85 & -1.11 & (1.36) & -0.82 & (1.01) & -0.27 & (0.99) \\
\hline & $25.0-29.9$ & 12 & -0.87 & $(0.89)$ & -0.88 & $(0.96)$ & -0.19 & (0.87) \\
\hline & $30.0 \leq$ & 2 & -1.20 & $(0.65)$ & -0.58 & $(0.62)$ & -0.18 & $(0.35)$ \\
\hline & F-test & \multicolumn{3}{|c|}{$1.1, p=0.35$} & \multicolumn{2}{|c|}{$1.45, p=0.23$} & \multicolumn{2}{|c|}{$0.37, p=0.77$} \\
\hline
\end{tabular}

Table 4: Mean HAZ, WAZ and WHZ of children according to their mothers' BMI

\section{Dietary intake and infant feeding practice}

Like in other areas of PNG, the study subjects took meals three times a day in both sites. Our dietary survey by 24-hour recall methods explored less availability of a variety of foods in rural NUKU, as well as a larger portion size of staple intake among mothers in urban POM.

The results of FFQ revealed that the main foods consumed daily were kaukau (sweet potato), rice, bread, biscuit and butter in urban POM and sago (a kind of palm) and kaukau, coconut and banana in rural NUKU. On the other hand, the consumption of the green leafy vegetable was relatively high in both sites; more than $90 \%$ and half of the mothers took green vegetable at least once a day in urban POM and rural NUKU, respectively). Main protein resources were fish, meat, egg and milk in POM while only fish was available locally in NUKU.

Characteristics of infant feeding practice were also quite different between two sites, except that most of mothers gave colostrum to their new-born babies in both sites (POM 89.5\%, NUKU 89.9\%). Early introduction of liquid and food (before 6 months of age) were typically observed among mothers in rural NUKU (89.2\%) (vs. 53.2\% in urban POM), where 73\% of mothers started giving foods from 4 months. Furthermore, 30.4\% of mother continues to give breast milk after two years old, which was not observed in urban POM. Complementary foods were consisted of kaukau, pumpkin, papaya, banana, egg in urban POM, whereas sago, kaukau, yam, banana and papaya were predominant in rural NUKU. Half of the study children were given powder milk daily in POM, which this proportion was only $10 \%$ in rural NUKU.

Table 5 shows the prevalence of stunting, underweight and wasting (WHZ $<-2)$ according to the timing of introduction of first food. Early introduction of the first liquid/food, other than breast milk, was associated with higher prevalence of under nutrition among children.

\begin{tabular}{|c|c|c|c|c|c|c|c|c|}
\hline \multirow[b]{2}{*}{$\begin{array}{l}\text { Age of } \\
\text { months* }\end{array}$} & \multicolumn{4}{|c|}{ Port Moresby } & \multicolumn{4}{|c|}{ Nuku } \\
\hline & $\mathbf{n}$ & $\begin{array}{l}\text { Stunting } \\
(\mathrm{HAZ}<-2)\end{array}$ & $\begin{array}{c}\text { Underweight } \\
\text { (WAZ<-2) }\end{array}$ & $\begin{array}{c}\text { Wasting } \\
(\mathrm{WHZ}<-2)\end{array}$ & n & $\begin{array}{l}\text { Stunting } \\
(\mathrm{HAZ}<-2)\end{array}$ & $\begin{array}{l}\text { Underweight } \\
\text { (WAZ<-2) }\end{array}$ & $\begin{array}{c}\text { Wasting } \\
(\mathrm{WHZ}<-2)\end{array}$ \\
\hline$<6$ months & 42 & $3(7.1 \%)$ & $1(2.4 \%)$ & $2(4.8 \%)$ & 96 & $27(28.1 \%)$ & $9(9.4 \%)$ & $2(2.1 \%)$ \\
\hline$\geq 6$ months & 37 & $0(0.0 \%)$ & $0(0.0 \%)$ & $1(2.7 \%)$ & 12 & $3(25.0 \%)$ & $1(8.3 \%)$ & $0(0.0 \%)$ \\
\hline
\end{tabular}

${ }^{*}$ Age of months when a mother started giving foods to a child for the first time

Table 5: Prevalence of under nutrition according to the timing of introducing the first food

\section{Discussion}

This study attempted to explore the nutritional situation in urban and rural areas of PNG. Overall, children and mothers were more disadvantaged in rural NUKU, than urban POM, in terms of both nutritional/physical status and food availability. Although nutritional status of children in urban POM was better than those in rural NUKU, higher susceptibility to the infectious diseases could suggest the fragility in their living environments in urban settings [16]. This was particularly obvious in poor households, due that high dependency of cash income would affect the food choice and health service utilization. On the other hand, only locally available foods were obtained in rural NUKU, due to the limited access to the markets. 
Stunting is a valuable proxy of deprivation, reflecting socio-economic factors and unhealthy living conditions [17,18]. In the study sites, the prevalence of stunting, underweight and wasting was lower than national average [1]. Since this study was conducted in the midst of the dry season, only for 2-3 months in a year, the dietary data appeared relatively good compared to those in the rainy season. It must be noted, however, that the amount of their intake of each food item (except for staple foods) was extremely small, and also that little variation was observed in the diets among the study households, especially in rural NUKU. Considering that the seasonality greatly affects the food availability, as well as the incidence of infectious diseases, our findings could have underestimated the actual nutritional vulnerability among the study children, particularly in terms of wasting.

One of the limitations of this study was selection bias, as the data collection was undertaken at the health centers in this study, instead of household visits, due to the security/safety reason. Consequently, mothers and children from the relatively better-off households who could regularly visit for the immunization might have been possibly sampled in this study. Our findings of the association between mothers' BMI and children's anthropometric status also suggest that high prevalence of obesity/overweight among study mothers could have been the reason of the low prevalence of undernutrition in urban POM. Yet, few children were identified as obesity in both sites.

High prevalence of overweight/obesity among mothers in urban POM was possibly due to a great dependency on energy-dense staple foods [19], with little physical activity in their daily lives. Adverse health effects of betel nut chewing habit have been documented, including higher risk of obesity, metabolic syndrome and low birth weight [20, 21]. However, this association was not observed in this study.

It is said that the growth retardation would occur as early as 6-12 months, mainly due to the inappropriate feeding practices and high exposure to infections $[14,18]$. According to the recommendation by WHO and UNICEF, the infants should be exclusively breastfed for at least the first 4 months, and if possible, up to the 6 months of age, followed by appropriate complementary feeding and continued breastfeeding for two years [22]. Our study, however, identified the common practices of early introduction of complementary foods and breastfeeding longer than recommended duration in rural NUKU. Our findings also suggested the adverse impact of early introduction of the first food on children's nutritional status. Furthermore, the use of powder milk observed among mothers in urban POM would implicate the problems associated with artificial feeding.

\section{Conclusion}

This study confirmed an urgent need of area-specific approach for "double burden of malnutrition", considering the differential regional characteristics affecting nutritional status of children and mothers in the study areas. PNG is characterized by its multiethnicity and diverse topography, and thus, it is essential to consider the different features of each site, so as to identify the problems of priority and the most vulnerable group. Actually, it is not easy to improve the self-sufficiency of foods in the areas where the most of the farmer engage in the sifting cultivation. The continuous efforts, therefore, will be required to enhance the agricultural sector, as well as health sector. These approaches include nutrition education for the mothers on the importance of exclusive breastfeeding and appropriate complementary food to be enhanced in the prenatal care service.

\section{Acknowledgement}

This study was partially supported by Research Grant from Japan Foundation of International Medical Research Cooperation, Japan. We would like to thank in especially Dr. Tadatoshi Kuratsuji (Former JICA Senior Volunteer, Adviser of Department of Health, PNG) for his generous field assistance at the initial stage of negotiation with Department of Heath PNG, as well as during the preliminary visit to NUKU in July 2010. We also thank the research assistants for their contribution to questionnaire interviews with mothers in each study site. Assistance of the staff of Well baby Clinic, Port Moresby General Hospital and the Nuku district health center during the data collection was gratefully acknowledged.

\section{References}

1. UNICEF (2009) The State of the World's Children Special Edition. UNICEF, New York.

2. Kuratsuji T (2009) Good Governance and Maternal, Neonatal \& Child Health in Papua New Guinea. Presented at The $18^{\text {th }}$ Symposium on the International Medical Cooperation "Maternal, Neonatal and Child Health from a Global Perspective".

3. Bourke RM, Allen MG (2000) An Overview of Food Security in PNG. Food Security for Papua New Guinea. Proceedings of the Papua New Guinea Food and Nutrition 2000 Conference, PNG University of Technology, Lae 451-6.

4. FAO (2003) Nutrition Country Profiles - Papua New Guinea.

5. WHO (2011) Papua New Guinea Country Health Information Profiles.

6. UNICEF (2004) Papua New Guinea National Micronutrient Survey 2005. Protocol.

7. Department of Health (2011) National Nutrition Survey Papua New Guinea, 2005. Pacific J Med Sci 8.

8. Okuda T, Kajiwara N, Date C, Sugimoto K, Rikimaru T, et al. (1981) Nutritional status of Papua New Guinea highlanders. J Nutr Sci Vitaminol (Tokyo) 27: 319-31.

9. Koishi H (1990) Nutritional Adaptation of Papua New Guinea highlanders. Eur J Clin Nutr. 44: 853-85.

10. Mueller I and Smith TA (1999) Patterns of child growth in Papua New Guinea and their relation to environmental, dietary and socioeconomic factors. PNG Med J 42: 94-113. 
11. The National Research Institute (2010) Papua New Guinea District and Provincial Profiles.

12. Mutambek J, Tumana C (2010) Malnutrition Status in Sandaun Province. Food Security for Papua New Guinea.

13. Gibson RS (1990) Principles of Nutritional Assessment. Oxford University Press.

14. Beaton GH, Kelly A, Kevany J, Martorell R, Mason J (1990) Appropriate use of anthropometric indices in children.

15. WHO Anthro for personal computers, version 3.2.2. Geneva (2011) World Health Organization.

16. Government of Papua New Guinea (2010) National Health Plan 2011-2020. Policies and Strategies.

17. Vella V, Tomkins A, Borghesi A, Migliori GB, Oryem VY (1994) Determinants of stunting and recovery from stunting in northwest Uganda. Int J Epidemiol. 23: 782-6.

18. Martorell R. Kettel L, Schroeder DG (1994) Reversibility of stunting; epidemiological findings in children from developing countries. Eur J Clin Nutr 48: S45-57.

19. FAO (2004) The Pacific Islands food composition tables.

20. Javed F, Al-Hezaimi K, Warnakulasuriya S (2012) Areca-nut chewing habit is a significant risk factor for metabolic syndrome: a systematic review. J Nutr Health Aging 16: 445-8.

21. Garg A, Chaturvedi P, Gupta CP (2014) A review of the systemic adverse effects of areca nut or betel nut. Indian J Med Paediatr Oncol. 35: 3-9.

22. BASICS (1999) Nutrition Essentials: A guide for health managers. WHO/UNICEF/BASICS. Geneva.

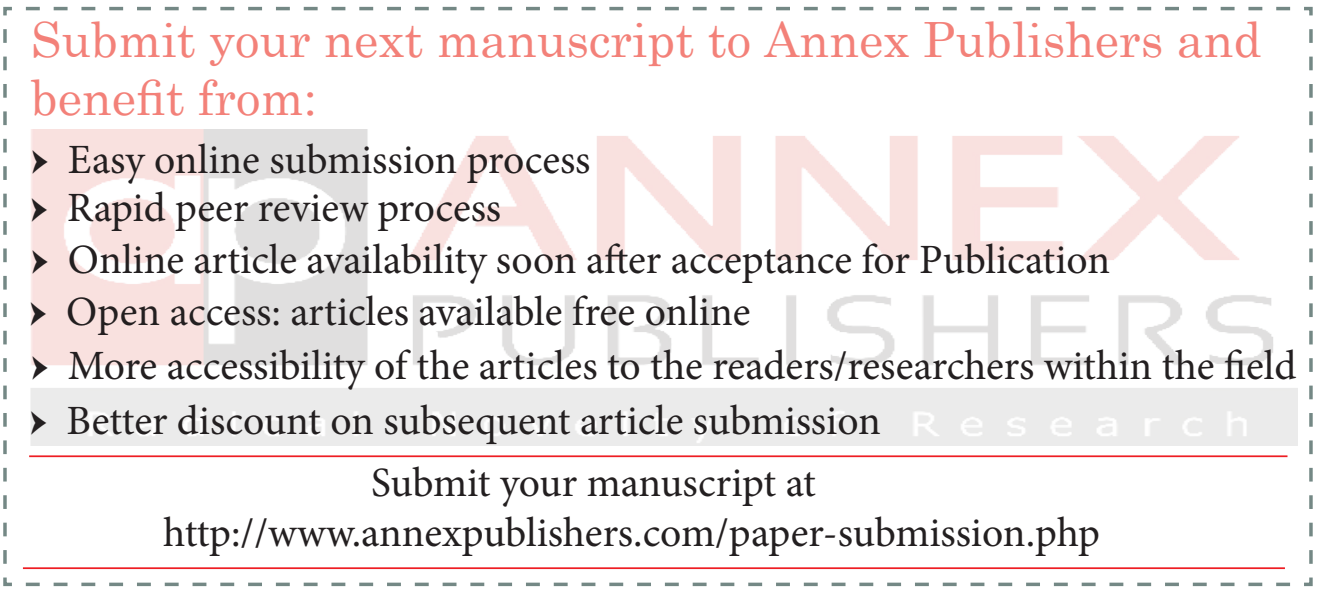

